\title{
Comparative Remineralization Efficacy of Topical NovaMin and Fluoride on Incipient Enamel Lesions in Primary Teeth: Scanning Electron Microscope and Vickers Microhardness Evaluation
}

\author{
Safaa Shihabi ${ }^{1} \quad$ Salma AlNesser ${ }^{1} \quad$ John C. Comisi ${ }^{2, \odot}$ \\ ${ }^{1}$ Department of Pediatric Dentistry, Faculty of Dentistry, Damascus \\ University, Damascus, Syria \\ 2Department of Oral Rehabilitation, Restorative Dentistry, Medical \\ University of South Carolina, James B. Edwards College of Dental \\ Medicine, Charleston, United States
}

\begin{abstract}
Address for correspondence John C. Comisi, DDS, Department of Oral Rehabilitation, James B. Edwards College of Dental Medicine, Medical University of South Carolina, Charleston, SC 29425, United States (e-mail: comisi@musc.edu).
\end{abstract}

Eur J Dent 2021;15:420-424
Abstract
Keywords
- fluoride
- NovaMin
- vickers surface
microhardness
- scanning electron microscope
- white spot lesions
- hydroxycarbonate apatite

Objective Evaluating the potential remineralization effect of NovaMin prophylaxis paste on artificial enamel lesions in primary teeth using Vickers microhardness and scanning electron microscope.

Materials and Methods Forty sound buccal and lingual surfaces of human primary canine teeth were randomly divided into two groups after creating artificially demineralized lesions (G1: NovaMin and G2: fluoride; 20 per group) and then treated with the respective remineralization agents. The remineralization cycle repeated twice daily for 10 days. The groups were evaluated with Vickers microhardness and scanning electron microscope before and after de/remineralization.

Results Statistically significant difference of microhardness was observed between demineralized enamel and remineralized enamel with group 1 and group $2(p=0.000$ and $p=0.000$, respectively). No statistically significant difference of microhardness was observed between two remineralized agents $(p=0.368)$.

Conclusion Within the limitation of this in vitro study, NovaMin enhances the remineralization process equally to fluoride.

\section{Introduction}

Initial carious lesions are represented clinically as white spot lesions (WSLs), which are softer than intact enamel and whiter when dried. ${ }^{1}$ Treating WSLs of primary teeth by traditional methods is considered a challenge, especially for uncooperative patients with early childhood caries (ECC). ${ }^{2}$ Applying remineralization agents to WSLs may prevent cavity formation and therefore preserve enamel integrity. ${ }^{3}$

In the remineralization of tooth structure, fluoride is considered the gold standard. Fluoride inhibits demineralization by forming fluorapatite crystals (FAP). These crystals are more resistant to acid attack compared with hydroxyapatite crystals. ${ }^{4}$ Furthermore, fluoride enhances the growth of new FAP, and it inhibits the activity of acid production by carious bacteria. ${ }^{5}$ High concentrations of fluoride are toxic, and levels even slightly above therapeutic levels can lead to fluorosis and therefore can limit its use. ${ }^{6}$ Recently, researchers are trying to find an alternative material that can provide beneficial remineralization effects without the potential dangers associated with fluoride.

NovaMin (calcium sodium phosphosilicate) is a synthetic and highly biocompatible material developed as bone regenerative and sensitivity reducing material. ${ }^{7}$ Recently, NovaMin has been introduced as a remineralization agent in

(c) 2020. European Journal of Dentistry.

This is an open access article published by Thieme under the terms of the Creative Commons Attribution-NonDerivative-NonCommercial-License, permitting copying and reproduction so long as the original work is given appropriate credit. Contents may not be used for commercial purposes, or adapted, remixed, transformed or built upon. (https://creativecommons.org/licenses/by-nc-nd/4.0/)

Thieme Medical and Scientific Publishers Pvt. Ltd., A-12, 2nd Floor, Sector 2, Noida-201301 UP, India 
toothpaste and prophy pastes. When exposed to the aqueous environment of the oral cavity, the sodium ions from NovaMin particles rapidly exchange with hydrogen in the tooth structure to release calcium and phosphate ions. This ion release causes a rapid increase in $\mathrm{pH}$ and the subsequent creation of a hydroxycarbonate apatite layer (HCA) on the tooth structure. HCA is chemically and structurally similar to natural biological apatite, ${ }^{8}$ which makes the use of NovaMin a potential substitute for fluoride in toothpaste.

To the best of our knowledge, this is the first study to compare the remineralization effect of NovaMin and fluoride application to primary teeth using Vickers surface microhardness testing and scanning electron microscope (SEM). The null hypothesis is that there is no significant difference between fluoride and NovaMin.

\section{Materials and Methods}

Twenty deidentified primary canines were selected, in accordance with the ethical treatment of human tissue ethical committee IRB approval 1818, from freshly extracted for orthodontic reasons without any visible caries, WSLs, cracks, or fractures under a stereoscopic microscope (Meiji, Japan) at $\times 2$ magnification. All teeth were then examined with laser fluorescence DIAGNOdent (Kavo, Germany) "wavelength 655 nm." Samples with DIAGNOdent values between 0 and 13 , which referred to intact enamel, were selected for this study according to the manufacturer's instructions.

\section{Specimens' Preparation}

The teeth were cleaned from residual soft tissue using a hand scaler (ck-6 [Zeffiro, Italy]) and then stored in $0.5 \%$ chloramine $\mathrm{T}$ in a plastic container for 1 week for disinfection.

The apical third of the teeth were removed, and the teeth then sectioned mesiodistally with a diamond disk. A $4 \times 4 \mathrm{~mm}$ square was created in the middle third of the labial and lingual surfaces using nail varnish and then fixed firmly into an acrylic block for secure handling. The baseline Vickers surface microhardness was measured for all specimens after numbering them from 1 to 40 .

\section{Baseline Vickers Surface Microhardness Testing}

A Vickers microhardness tester machine (Galilio, Italy) was used to determine the hardness values for each specimen before de/remineralization cycling.

A load of $100 \mathrm{~g}$ at an angle of 136 degrees was applied

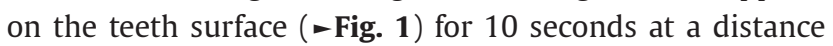

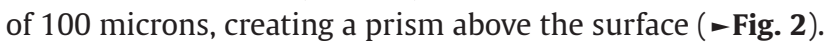
Therefore, SMH was measured according to the equation:

$$
\mathrm{SMH}=\frac{1,854 \times \mathrm{p}}{\mathrm{D}^{2}}
$$

$\mathrm{P}$ (power): the applying load.

$\mathrm{D}$ (diameter): the diameter of the prism.

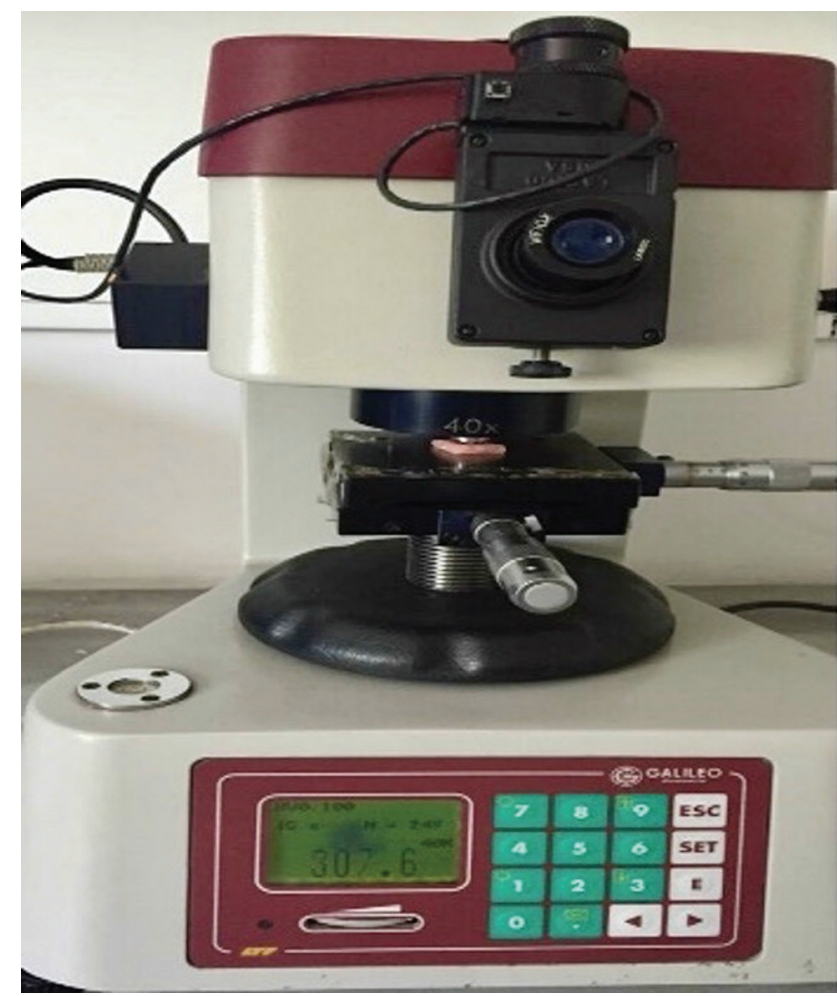

Fig. 1 The applying load on the tooth surface.

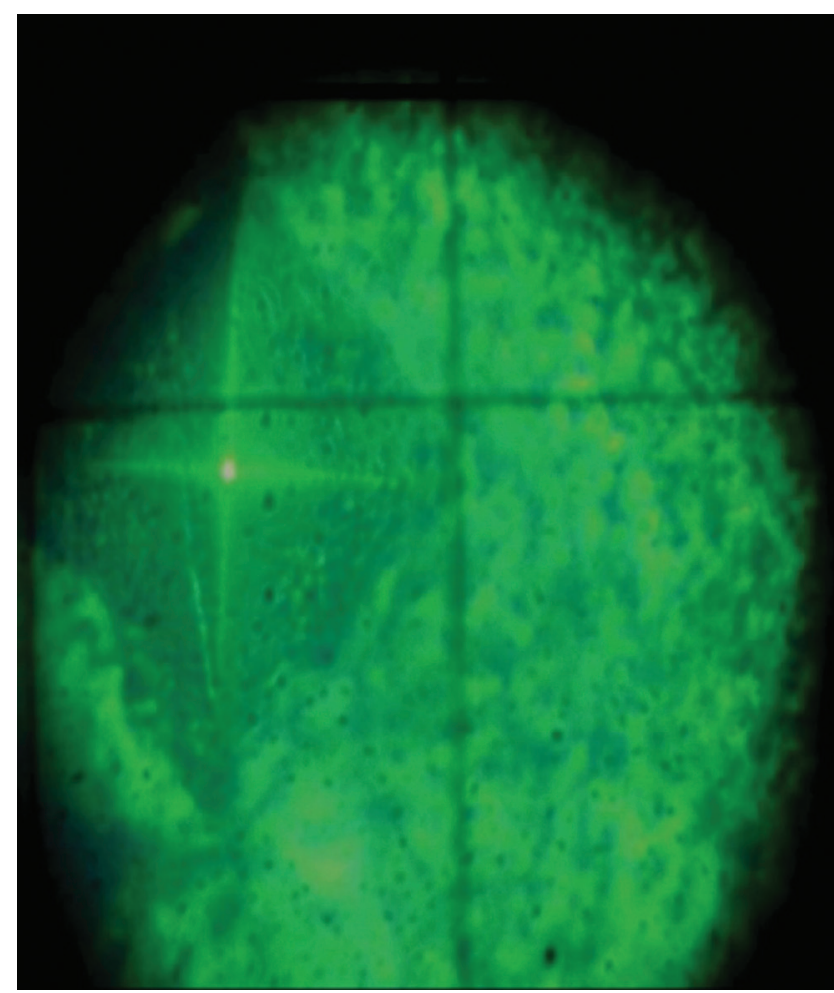

Fig. 2 The forming prism above the tooth surface.

\section{Demineralization Cycle}

Teeth were immersed for 1 hour in numbered plastic vials containing $20 \mathrm{~mL}$ of demineralization solution $(2 \mathrm{mM}$ $\mathrm{CaCl}_{2}, 2 \mathrm{mM} \mathrm{NaH}_{2} \mathrm{Po}_{4}, 50 \mathrm{mM} \mathrm{CH}{ }_{3} \mathrm{COOH}$, with the addition 
of $0.1 \mathrm{M} \mathrm{NaOH}$ to $\mathrm{pH} 4.55$ ). Specimens were then rinsed with $10 \mathrm{~mL}$ deionized water and immersed for 22 hours in $20 \mathrm{~mL}$ of remineralization solution $\left(2 \mathrm{mM} \mathrm{CaCl}_{2}, 2 \mathrm{mM}\right.$ $\mathrm{NaH}_{2} \mathrm{Po}_{4}$, with the addition of $0.1 \mathrm{M} \mathrm{NaOH}$ to $\mathrm{pH} 6.8$ ) at room temperature. ${ }^{9}$ The teeth were then subjected to the de/ remineralization solutions three times to create artificial carious lesions. ${ }^{9}$ Then SMH was measured to all specimens under the same conditions. Samples were then stored in deionized water, which was replaced daily until remineralization agents were applied.

Specimens were then randomly divided into two groups as follows:

Group 1: Novamin containing paste NUPRO (Prophylaxis Paste with NovaMin; Dentsply International, United States; - Table 1).

Group 2: Fluoride 1.23\% (DEFEND Prophylaxis Paste; Mydent International, United States; - Table 1).

\section{Remineralization Cycle}

Group 1: $0.5 \mathrm{~g}$ of NUPRO paste was applied with a rubber cup to each tooth for 2 minutes in a clockwise direction. Then the teeth were immersed in deionized water for 2 minutes and then gently rinsed with deionized water.

Group 2: The fluoride-containing DEFEND paste (1.23\%) was applied in the same manner as in group 1.

The remineralization cycle was repeated twice daily for 10 days. ${ }^{9}$ All teeth were then soaked in deionized water until SMH was measured to determine the acquired microhardness.

\section{Statistical Analysis}

Kolmogorov-Simonov was used to determine if the data were normally distributed. Mann-Whitney $U$ test was used to identify statistically significant differences in enamel microhardness between intact and demineralized specimens, and between demineralized and remineralized samples treated with NUPRO paste and DEFEND paste; and the difference between NUPRO paste and DEFEND fluoride paste as a remineralization agent.

Data were analyzed using SPSS version 23 (IBM Corp.; Armonk, New York, United States), where the $p$-value was set at 0.05 , and the level of confidence was set at $95 \%$.

Table 1 The ingredients of the prophylaxis paste used in this study

\begin{tabular}{|l|l|}
\hline & Ingredients \\
\hline $\begin{array}{l}\text { (Prophylaxis paste, } \\
\text { DEFEND, Mydent } \\
\text { International, } \\
\text { United States) }\end{array}$ & $\begin{array}{l}\text { 1.23\% fluoride ion, glycerin, } \\
\text { sodium silicate, titanium dioxide, } \\
\text { methyl salicylate, water, sodium } \\
\text { carboxymethylcellulose, sodium } \\
\text { saccharin, flavor }\end{array}$ \\
\hline $\begin{array}{l}\text { NUPRO (prophylaxis } \\
\text { paste with } \\
\begin{array}{l}\text { NovaMin; Dentsply } \\
\text { International, } \\
\text { United States). }\end{array}\end{array}$ & $\begin{array}{l}\text { Calcium sodium phosphosilicate } \\
\text { (NovaMin), glycerin, sodium silicate, } \\
\text { titanium dioxide, methyl salicylate, } \\
\text { water, sodium carboxymethylcellulose, } \\
\text { sodium saccharin, flavor }\end{array}$ \\
\hline
\end{tabular}

\section{Results}

Descriptive results of testing-minimum, maximum, mean, standard deviation of microhardness including intact, demineralized, and remineralized enamel with NUPRO paste (Group 1) and DEFEND Fluoride paste (Group 2)-are shown in (-Table 2).

The Mann-Whitney U test showed (1) a statistically significant difference in the microhardness of intact enamel specimen when compared with demineralized enamel specimen ( $p=0.000)$; (2) a statistically significant difference in microhardness between demineralized enamel and both remineralized enamel with either Group 1 or Group 2 ( $p=0.000$ and $p=0.000$, respectively); and (3) no statistically significant difference in microhardness values of remineralization observed with NUPRO paste (Group 1) and fluoride paste (Group 2) (-Table 3 ).

\section{Scanning Electron Microscope Images}

The samples were analyzed under SEM (VEGA II; TESCAN, Czech Republic) at $\times 70$ magnification:

- SEM evaluation of the intact enamel before demineralization showed regular deposition of enamel rods and prisms (-Fig. 3).

- The enamel surface after demineralization presented a honeycomb-like appearance, created by collapsing enamel rods, prism irregularity, and the disorientation of hydroxyapatite crystals (- Fig. 4 ).

- The enamel treated with the NUPRO NovaMin containing paste lead to deposition of the material over enamel as a dark, smooth, and uniform thickness area ( - Fig. 5).

- Enamel treatment with DEFEND fluoride formed an irregular layer of FAP ( - Fig. 6).

\section{Discussion}

$\mathrm{Re} /$ demineralization is a dynamic process that occurs in the oral cavity over time. ${ }^{10}$ When the delicate balance between them breaks down, a lesion will be formed on tooth surfaces as a WSL. Supplying these WSLs with calcium and phosphate ions will help reverse cavity formation. ${ }^{11,12}$ Thus, this study aimed to determine the effect of calcium sodium phosphosilicate (NovaMin) in the remineralization of tooth structure.

The organic content of the primary tooth enamel is higher than that of permanent tooth enamel so that it may be more susceptible to caries. There are no studies that have evaluated NovaMin versus fluoride efficacy in primary teeth; therefore, we selected the anterior primary teeth in this experimental study. ${ }^{13}$

Vickers surface microhardness testing was used to evaluate the remineralization effect. It is a nondestructive, reliable, rapid, and economical method of testing. ${ }^{14}$

The results of this study showed that the SMH values after demineralization were less than initial SMH, which is a statistically significant difference. Therefore, the demineralization cycle created WSLs, which is similar to Haghgoo et al and Creanor et al results. ${ }^{8,15}$ Moreover, the SMH values 
Table 2 The descriptive results of the microhardness of study specimens $\left(\mathrm{g} / \mathrm{mm}^{2}\right)$

\begin{tabular}{|l|l|l|l|l|}
\hline Study specimens & $\boldsymbol{n}$ & Minimum & Maximum & Mean \pm SD \\
\hline Intact enamel & 40 & 215.40 & 393.00 & $319.4 \pm 53.7$ \\
\hline Demineralized enamel & 40 & 112.20 & 277.00 & $142.7 \pm 46.3$ \\
\hline NUPRO paste (Group 1) & 20 & 245.90 & 450.40 & $368.8 \pm 69.03$ \\
\hline Fluoride paste (Group 2) & 20 & 254.60 & 596.30 & $365.7 \pm 104.7$ \\
\hline
\end{tabular}

Abbreviation: SD, standard deviation.

Table 3 The results of Mann-Whitney $U$ test regarding the microhardness between intact and demineralized specimens; demineralized enamel and remineralizing agent (NUPRO or fluoride); and remineralizing agent pastes (NUPRO and fluoride, g/mm²)

\begin{tabular}{|l|l|l|l|}
\hline Pairwise comparison & $\boldsymbol{n}$ & Mean rank & $\boldsymbol{p}$-Value \\
\hline Intact enamel & 40 & 59.70 & 0.000 \\
\hline Demineralized enamel & 40 & 21.30 & 0.000 \\
\hline Demineralized enamel & 20 & 10.70 & \\
\hline Remineralization with NUPRO (Group 1) & 20 & 30.30 & 0.000 \\
\hline Demineralized enamel & 20 & 10.90 & \\
\hline Remineralization with fluoride (Group 2) & 20 & 30.10 & 0.368 \\
\hline Remineralization with NUPRO (Group 1) & 20 & 22.10 & 18.90 \\
\hline Remineralization with fluoride (Group 2) & 20 & \\
\hline
\end{tabular}

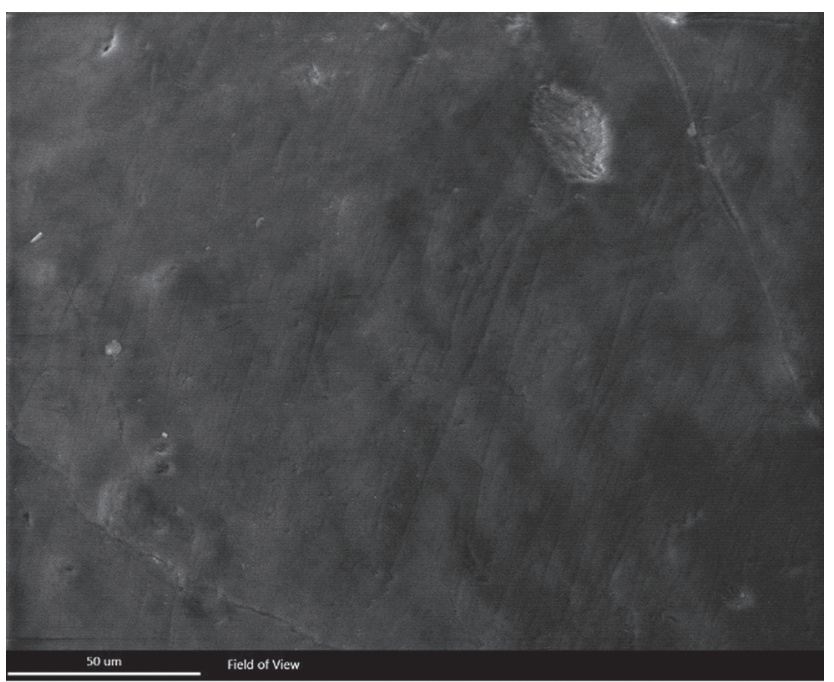

Fig. 3 Intact enamel surface.

after remineralization increased compared with SMH values after demineralization. This result is a statistically significant difference and demonstrates that fluoride and NovaMin both trigger the remineralization process, as illustrated in the individual testing of these agents in prior studies with both permeant and primary teeth. . $^{9} 16,17,18,19$

NovaMin is an inorganic and synthetic compound, which releases sodium, calcium, phosphate, and silica when it exposed to an aqueous media, increases $\mathrm{pH}$ and forms Hydroxycarbonateapatite crystals, and thus initiates the remineralization process. ${ }^{20,21,22}$

The pairwise comparisons showed of this study illustrate that there are no statistically significant differences between NovaMin and fluoride in SMH values. Although

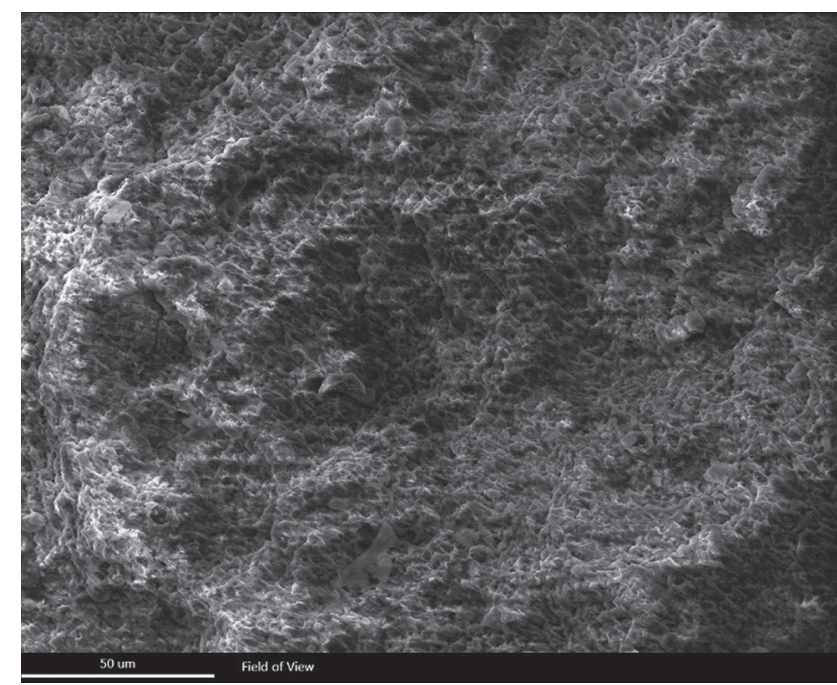

Fig. 4 Demineralized enamel surface.

NovaMin did not offer further remineralization effect than did fluoride, this study shows it equally beneficial. The elimination of potential fluoride toxicity, and fluorosis of young children's teeth from overingestion of fluoride toothpaste during daily tooth brushing, could be one of the benefits in use NovaMin containing paste instead of fluoride.

\section{Conclusion}

The use of NovaMin containing paste in remineralization of incipient enamel lesions is a promising treatment due to its safety, but further studies on primary teeth should be taken to confirm its efficacy. 


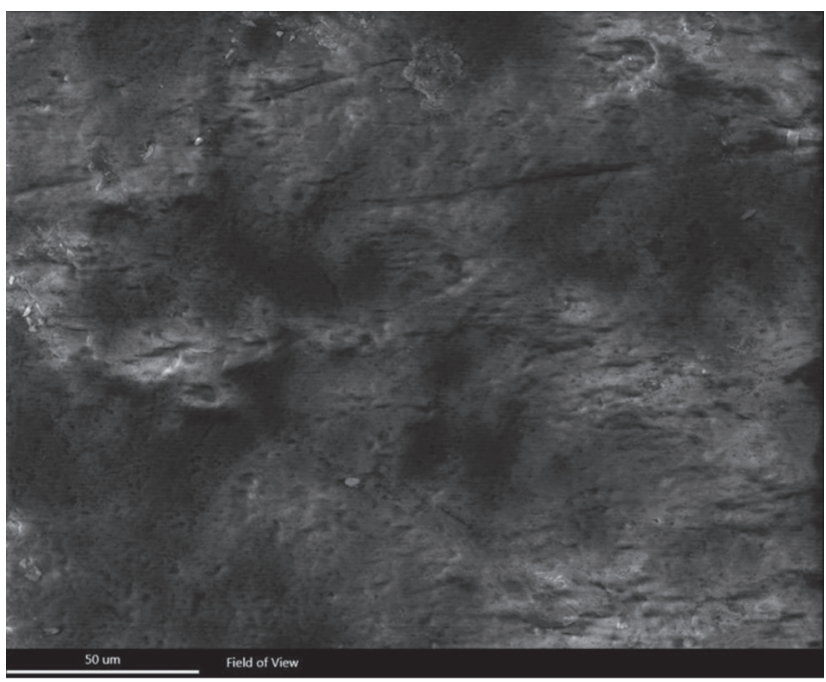

Fig. 5 Enamel surface after fluoride application.

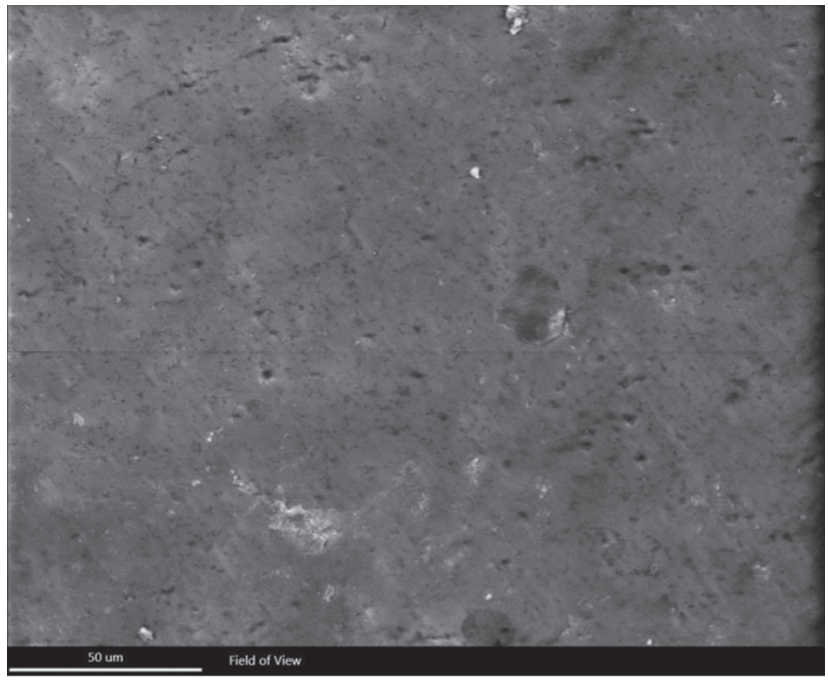

Fig. 6 Enamel surface after NovaMin treatment.

\section{Authors' Contributions}

S.S. and S.A. supported in research concept and design, collection of data, and writing of the manuscript. J.C.C. was involved in manuscript revision and editing.

\section{Funding}

This study received its financial support from Faculty of Dentistry, Damascus University.

\section{Conflict of Interest}

None declared.

\section{References}

1 Sarkis H, Ghaleb M, Dabbagh S. Harouny. White spot lesions: Resin infiltration technique. Int Arab J Dent 2017;81:10-14

2 Townsend JA, Wells MH, Behavior guidance of the pediatric dental patient. In: Pediatric Dentistry. 2019 ;Elsevier: -352-357

3 Roopa KB, Pathak S, Poornima P, Neena I. White spot lesions: a literature review. J Paediatr Dent 2015;31:1-7
4 Arifa MK, Ephraim R, Rajamani T. Recent advances in dental hard tissue remineralization: a review of literature. Int J Clin Pediatr Dent 2019;12(2):139-144

5 Soi S, Vinayak V, Singhal A, Roy S. Fluorides and their role in demineralisation and remineralisation. J Dent Sci Oral Rehabil 2013;14:19-21

6 Ullah R, Zafar MS, Shahani N. Potential fluoride toxicity from oral medicaments: a review. Iran J Basic Med Sci 2017;20(8):841-848

7 Layer TM. Development of a fluoridated, daily-use toothpaste containing NovaMin technology for the treatment of dentin hypersensitivity. J Clin Dent 2011;22(3):59-61

8 Haghgoo R, Ahmadvand M, Moshaverinia S. Remineralizing effect of topical NovaMin and nano-hydroxyapatite on caries-like lesions in primary teeth. J Contemp Dent Pract 2016;17(8):645-649

9 Gangwar A, Jha KK, Thakur J, Nath M. In Vitro evaluation of remineralization potential of novamin on artificially induced carious lesions in primary teeth using scanning electron microscope and vickers hardness. Indian J Dent Res 2019;30(4):590-594

10 Walsh LJ. Contemporary technologies for remineralization therapies: a review. Int Dent SA 2009;116:6-16

11 Jefferies SR. Advances in remineralization for early carious lesions: a comprehensive review. Compend Contin Educ Dent 2014;35(4):237-243, quiz 244

12 Cochrane NJ, Cai F, Huq NL, Burrow MF, Reynolds EC. New approaches to enhanced remineralization of tooth enamel. J Dent Res 2010;89(11):1187-1197

13 De Menezes Oliveira MAH, Torres CP, Gomes-Silva JM, et al. Microstructure and mineral composition of dental enamel of permanent and deciduous teeth. Microsc Res Tech 2010;73(5):572-577

14 Şakar-Deliormanli A, Güden M. Microhardness and fracture toughness of dental materials by indentation method. J Biomed Mater Res B Appl Biomater 2006;76(2):257-264

15 Creanor SL, Awawdeh LA, Saunders WP, Foye RH, Gilmour $\mathrm{WH}$. The effect of a resin-modified glass ionomer restorative material on artificially demineralised dentine caries in vitro. J Dent 1998;26(5-6):527-531

16 Wang Y, Mei L, Gong L, et al. Remineralization of early enamel caries lesions using different bioactive elements containing toothpastes: an in vitro study. Technol Health Care 2016;24(5):701-711

17 Manoharan V, Kumar RK, Sivanraj AK, Arumugam SB. Comparative evaluation of remineralization potential of casein phosphopeptide-amorphous calcium fluoride phosphate and novamin on artificially demineralized human enamel: an in vitro study. Contemp Clin Dent 2018;9(Suppl 1) :S58-S63

18 Krishnan G, George S, Anandaraj S, John SA, Mathew V, Shanavas NM. Efficacy of four remineralizing agents on primary teeth: in vitro evaluation using microhardness testing and quantitative light-induced fluorescence. Pediatr Dent 2017;39(3):233-237

19 Aras A, Celenk S, Dogan MS, Bardakci E. Comparative evaluation of combined remineralization agents on demineralized tooth surface. Niger J Clin Pract 2019;22(11):1546-1552

20 Gjorgievska E, Nicholson JW. Prevention of enamel demineralization after tooth bleaching by bioactive glass incorporated into toothpaste. Aust Dent J 2011;56(2):193-200

21 Khijmatgar S, Reddy U, John S, Badavannavar AN, D Souza T. Is there evidence for Novamin application in remineralization?: a systematic review. J Oral Biol Craniofac Res 2020;10(2):87-92

22 Hench LL, Andersson Ö, Bioactive Glasses: An Introduction to Bioceramics 1993; World Scientific:41-62 